\title{
Reduced Tyrosine Kinase Activity of the Insulin Receptor in Obesity-Diabetes Central Role of Tumor Necrosis Factor-a
}

\author{
Gökhan S. Hotamisligil, Adriane Budavari, David Murray, and Bruce M. Spiegelman
}

Dana-Farber Cancer Institute and Department of Cell Biology, Harvard Medical School, Boston, Massachusetts 02115

\begin{abstract}
Insulin resistance is an important metabolic abnormality often associated with infections, cancer, obesity, and especially non-insulin-dependent diabetes mellitus (NIDDM). We have previously demonstrated that tumor necrosis factor- $\alpha$ produced by adipose tissue is a key mediator of insulin resistance in animal models of obesity-diabetes. However, the mechanism by which TNF- $\alpha$ interferes with insulin action is not known. Since a defective insulin receptor (IR) tyrosine kinase activity has been observed in obesity and NIDDM, we measured the IR tyrosine kinase activity in the Zucker (fa/fa) rat model of obesity and insulin resistance after neutralizing TNF- $\alpha$ with a soluble TNF receptor (TNFR)-lgG fusion protein. This neutralization resulted in a marked increase in insulin-stimulated autophosphorylation of the IR, as well as phosphorylation of insulin receptor substrate 1 (IRS-1) in muscle and fat tissues of the fa/fa rats, restoring them to near control (lean) levels. In contrast, no significant changes were observed in insulin-stimulated tyrosine phosphorylations of IR and IRS-1 in liver. The physiological significance of the improvements in IR signaling was indicated by a concurrent reduction in plasma glucose, insulin, and free fatty acid levels. These results demonstrate that TNF- $\alpha$ participates in obesity-related systemic insulin resistance by inhibiting the IR tyrosine kinase in the two tissues mainly responsible for insulin-stimulated glucose uptake: muscle and fat. (J. Clin. Invest. 1994. 94:15431549.) Key words: cytokines - metabolism • insulin action • insulin resistance $\cdot$ NIDDM
\end{abstract}

\section{Introduction}

Insulin resistance, a subnormal biological response to insulin, is a systemic phenomenon associated with several diseases including chronic infections $(1)$, cancer $(2,3)$, obesity, and especially non-insulin-dependent diabetes mellitus (NIDDM) ${ }^{1}$ (4, $5)$. NIDDM typically involves defects in both insulin action and insulin secretion, and improvement of insulin resistance

Address correspondence to Dr. Bruce M. Spiegelman, Dana-Farber Cancer Institute, 44 Binney Street, Boston, MA 02115.

Received for publication 30 March 1994 and in revised form 23 June 1994.

1. Abbreviations used in this paper: IR, insulin receptor; NIDDM, noninsulin-dependent diabetes mellitus; pTyr, phosphotyrosine; TNFR, TNF receptor.

J. Clin. Invest.

(C) The American Society for Clinical Investigation, Inc. 0021-9738/94/10/1543/07 \$2.00

Volume 94, October 1994, 1543-1549 offers a promising approach to the treatment of this common metabolic disease $(4,5)$. Although several defects that could play important roles in impaired insulin action have been described, the molecular mechanisms that lead to the most common forms of insulin resistance have not been clearly understood (5).

Recently, we have shown that TNF- $\alpha$ is an important mediator of insulin resistance in obese animals through its overexpression from fat tissue (6-8). Neutralization of TNF- $\alpha$ with a soluble TNF receptor-immunoglobulin $G$ fusion protein (TNFR-IgG) in fa/fa rats resulted in an improved stimulation of peripheral glucose uptake in response to insulin (6). Moreover, chronic administration of TNF- $\alpha$ has also been shown to induce peripheral insulin resistance in normal rats (9). However, the mechanism(s) by which TNF- $\alpha$ interferes with insulin action in obesity is not known.

Previously it has been shown that TNF- $\alpha$ causes downregulation of the insulin-regulable glucose transporter (Glut4) expression in cultured adipocytes and muscle cells $(6,10,11)$. Since Glut4 is also known to be deficient in adipose tissues of certain obese animal models as well as humans with NIDDM $(4,12,13)$, it is possible that TNF-mediated insulin resistance in these disorders may also involve the regulation of Glut4 expression. However, two pieces of evidence obtained in experiments using obese animals and cultured adipocytes suggested that additional steps in insulin action might be targeted by TNF$\alpha$. First, TNF- $\alpha$ strongly inhibited insulin-stimulated glucose uptake in cultured adipocytes at doses that do not affect cellular content of Glut4 protein (14). Second, the increases in insulin sensitivity in fa/fa rats upon TNF neutralization occurred in the absence of any quantitative changes in Glut4 (data not shown). Moreover, Glut 4 content of muscle tissue, the major site for glucose disposal, is not decreased in human NIDDM (4), suggesting that the changes in Glut4 content is unlikely to be a major determinant of insulin resistance in these disorders. These observations directed us to examine the effects of TNF- $\alpha$ on insulin signaling cascades.

The binding of insulin to its receptor initiates a phosphorylation cascade, which starts with autophosphorylation of the insulin receptor (IR) on multiple tyrosine residues of the $\beta$ subunit and subsequent activation of the receptor tyrosine kinase towards cellular substrates, such as IRS-1 and Shc (15-18). Mutagenesis studies and naturally occurring mutations demonstrate that the IR tyrosine kinase activity is an absolute requirement for the biological activities of insulin (18). Recent studies on cultured adipocytes and hepatoma cells showed that TNF- $\alpha$ has a profound effect on insulin receptor signaling $(14,19)$. Chronic exposure of adipocytes to low doses of TNF- $\alpha$ causes a dramatic decrease in the insulin-stimulated autophosphorylation of the IR and phosphorylation of IRS-1 (14). This decrease in the catalytic efficiency of the IR correlated with strong inhibition of insulin-stimulated glucose uptake. Similar findings were also reported in hepatoma cells, although the effects of TNF- $\alpha$ were observed acutely (19). 
The TNF- $\alpha$-induced abnormalities in IR tyrosine kinase activity observed in cultured cells are very similar to the defects demonstrated in the proximal steps of insulin signaling in NIDDM in both humans and rodents (20-23). Studies on insulin-stimulated autophosphorylation of IR and phosphorylation of IRS-1 have shown significant decreases in obesity/diabetes syndromes $(20,21)$. In addition, it has been recently demonstrated that stimulation of PI3-kinase activity by insulin is also decreased in rodent models of obesity and insulin resistance $(22,23)$. We have therefore asked in this study whether TNF$\alpha$ plays a role in the insulin resistance of obesity-diabetes syndromes through inhibition of IR-mediated phosphorylations. We demonstrate here that neutralization of TNF- $\alpha$ in obese and insulin resistant $\mathrm{fa} / \mathrm{fa}$ rats dramatically increases the insulin stimulated phosphorylations of IR and IRS-1 in fat and muscle tissues. These effects are limited to the obese/diabetic animals where TNF- $\alpha$ overexpression is observed.

\section{Methods}

Animals and reagents. Specific pathogen-free, male Zucker obese (fa/ fa) rats and their lean controls $(+/$ ? $)$ were purchased from Charles River Laboratories (Wilmington, MA). Soluble TNFR-IgG was a gift from Genentech, Inc. (San Francisco, CA). Recombinant human insulin (Humulin R) was obtained from Eli Lilly \& Co. The anti-IR monoclonal antibody was purchased from Oncogene Sciences (Manhasset, NY); the anti-IR polyclonal antibody was a gift from Dr. C. Ronald Kahn (Joslin Diabetes Center, Boston, MA) ; the anti-IRS-1 antibodies were gifts from Dr. Morris F. White (Joslin Diabetes Center) and anti-phosphotyrosine (pTyr) monoclonal antibody was a gift from Dr. Thomas Roberts (Dana Farber Cancer Institute, Boston, MA).

Neutralization of TNF- $\alpha$ in Zucker rats and assays for in vivo measurement of insulin-stimulated phosphorylations. On arrival, rats were housed for at least $1 \mathrm{wk}$ before experimental procedures and fed standard rodent chow and water ad libitum. TNFR-IgG (200 $\mu \mathrm{g} /$ injection per obese rat and $150 \mu \mathrm{g} /$ injection per lean rat) or vehicle (20\% glycerol) was administered intravenously for three consecutive days (6). On day 4 (after a 6-h fast) rats were anesthetized with ketamine and xylasine (intramuscular), the abdominal cavity was opened, and insulin (100 $\mathrm{mU} / \mathrm{kg}$ ) or saline was injected through the portal vein (21). In all experiments, liver, fat (epididymal), and muscle (hindlimb) tissues were removed and frozen immediately in liquid nitrogen, 30,100, and $120 \mathrm{~s}$ after the intraportal injection, respectively. The insulin dose and time points were selected to favor maximal insulin stimulation, as previously described (21). Blood samples were collected from each animal before and after the TNFR-IgG (or vehicle) treatments and after the intraportal insulin or vehicle infusions.

Preparation of protein extracts from fat, muscle, and liver. Frozen tissues were ground into a fine powder with a mortar and pestle and then homogenized with a Polytron homogenizer at $4^{\circ} \mathrm{C}$ in 6 (for muscle and fat) or $\mathbf{1 0}$ (for liver) times the tissue volume of homogenization buffer (1\% Triton-X 100, $50 \mathrm{mM}$ Hepes, $\mathrm{pH} \mathrm{7.4,} 100 \mathrm{mM}$ sodium pyrophosphate, $100 \mathrm{mM}$ sodium fluoride, $10 \mathrm{mM}$ EDTA, $10 \mathrm{mM}$ sodium vanadate, $2 \mathrm{mM}$ PMSF and $0.1 \mathrm{mg} / \mathrm{ml}$ aprotinin). All extracts were centrifuged at $55,000 \mathrm{rpm}$ for $60 \mathrm{~min}$ at $4^{\circ} \mathrm{C}$, and the supernatants were collected for further analysis (21).

Analysis of insulin receptor and IRS-1 phosphorylation. Two $\mathrm{mg}$ of extract protein was immunoprecipitated overnight at $4^{\circ} \mathrm{C}$ by the addition of $1 \mu \mathrm{g} / \mathrm{ml}$ monoclonal anti-IR or anti-IRS-1 antibodies. Immune complexes were collected on protein A-Sepharose beads (Pharmacia Fine Chemicals, Piscataway, NJ), washed three times in RIPA buffer $(0.15$ $\mathrm{M} \mathrm{NaCl}, 10 \mathrm{mM}$ phosphate buffer, $\mathrm{pH} 7.0,1 \% \mathrm{NP}-40,1 \%$ sodium deoxycholate, $0.1 \%$ sodium dodecyl sulfate), boiled in loading buffer, and loaded onto $7.5 \%$ SDS-PAGE gels. The proteins were transferred to nitrocellulose and Western blot analysis was performed (Promega, Madison, WI) using a 1:2,000 dilution of a monoclonal anti-pTyr, a
1:100 dilution of a polyclonal anti-IR or a 1:500 dilution of a polyclonal anti-IRS-1, as the primary antibody, followed by alkaline phosphataseconjugated anti-mouse or anti-rabbit IgG antibodies (Promega) for detection $(24,25)$.

Other methods. Plasma glucose levels were measured using a Beckman automated glucose analyzer and insulin concentrations were determined by radioimmunoassay (Linco Research, St. Louis, MO). Plasma TNFR-IgG concentrations were determined by ELISA (Bender Medsystems). Triglyceride and free fatty acid analyses were performed using the Sigma Chemical Co. (St. Louis, MO) and Waco Bioproducts (Richmond, VA) assay systems, respectively. Quantitation of western blots were performed by using a digital scanner (Abaton Scan 300/GS, Chicago, IL) and the image 1.33 image analysis program. Statistical analysis of the data was performed using the StatView $512+$ program. The values are represented as mean $\pm \mathrm{SE}$, and $P$ values are for two-tailed student $t$ test.

\section{Results}

Effects of neutralization of TNF- $\alpha$ on insulin-stimulated tyrosine phosphorylation of IR and IRS-1. To determine the effects of TNF neutralization on the ability of insulin to stimulate the tyrosine phosphorylation of the IR, we immunoprecipitated insulin receptors from protein extracts prepared from fat, muscle, and liver tissues of vehicle or insulin-stimulated individual animals and immunoblotted with anti-pTyr antibodies (see Methods). Without insulin stimulation, we did not detect tyrosine phosphorylated IR from any of the animals examined (Fig. 1). After insulin stimulation, the phosphorylation of the $95-\mathrm{kD} \beta$ subunit of the IR became apparent in fat, muscle, and liver tissues of both lean and obese animals (Fig. 1, lanes 2, 7, and 8). However, as expected from their insulin-resistant status, obese $\mathrm{fa} / \mathrm{fa}$ rats had significantly lower levels of insulin-stimulated autophosphorylation of IR compared to their lean littermates (Fig. 1, lanes 2 vs. 7 and 8 ). These decreases were $64 \pm 6 \%$ in fat $(P=0.008), 68.5 \pm 3.5 \%$ in muscle $(P=0.002)$, and $35 \pm 10 \%$ in liver $(P=0.05)$ tissues $(n=4$ in each group).

Neutralization of TNF- $\alpha$ via administration of the TNFRIgG led to a striking improvement in the insulin-stimulated IR phosphorylation in both fat and muscle tissues of obese rats compared with rats injected with the vehicle alone (Fig. $1, n=$ 4 in control and 6 in TNFR-IgG-treated group). Densitometric analysis showed that neutralization of TNF- $\alpha$ increased stimulation of IR phosphorylation by $42.2 \%$ in fat $(P=0.03)$ and by $55.2 \%$ in muscle $(P=0.005)$. The extent of insulin-stimulated phosphorylations in fat and muscle tissues of TNFR-IgGtreated obese animals approached the levels observed in their lean littermates. It is worth noting that increased tyrosine phosphorylation was observed in each animal receiving the neutralizing molecule. A small increase was also observed in liver (11\%) but this change was not statistically significant.

Similar to the results observed for the IR, we did not observe tyrosine phosphorylated IRS-1 without insulin injection in fat and muscle tissues, as determined by immunoprecipitations of IRS-1 followed by immunoblottings with anti-pTyr antibodies. However, there was a low level of tyrosine phosphorylation of IRS-1 in liver before insulin stimulation (Fig. 2, lanes 1 and 3-6). After intraportal administration of insulin, an increase was observed in tyrosine phosphorylation of IRS-1 in all animals. Relative to the lean animals, downregulation of insulinstimulated IRS-1 phosphorylation was observed in control fa/ fa rats (Fig. 2, lanes 2 vs 7 and 8 ). Compared with the lean animals $(n=4)$, insulin-stimulated IRS-1 phosphorylation was 


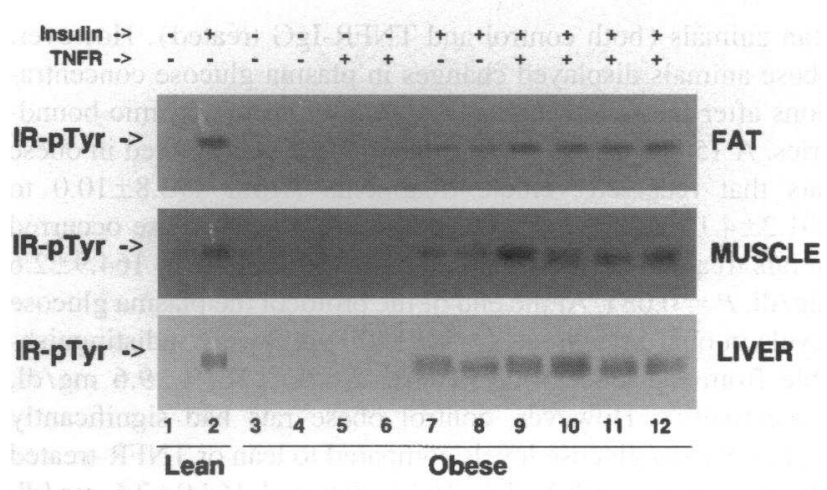

Figure 1. Effects of TNF- $\alpha$ neutralization on insulin-stimulated autophosphorylation of IR in tissues from obese $(\mathrm{fa} / \mathrm{fa})$ Zucker rats. The protein extracts were prepared from tissues of lean and obese Zucker rats, before (insulin -) or after (insulin + ) intraportal insulin administration, as described in Methods. The animals which were treated with TNFR-IgG to neutralize TNF- $\alpha$ are marked as TNFR $(+)$ and the controls as TNFR $(-)$. Lanes 1 and 2 show the level of insulin-stimulated tyrosine phosphorylation of IR (IR-pTyr) in lean rats. Lanes 3-6 demonstrate the lack of IR phosphorylation at the basal state (before insulin administration ) in both control and TNFR-IgG treated obese animals. Lanes 7-12 compare phosphorylation of IR in control obese (vehicletreated, lanes 7 and 8 ) with TNF-neutralized obese (TNFR-treated, lanes 9-12) rats. A steady-state blood concentration of TNFR-IgG was established in both lean and obese animals $(25.7 \pm 3.5$ and $22.9 \pm 2.2 \mathrm{ng} / \mathrm{ml}$, respectively). After intraportal insulin administration the serum insulin levels were $666.5 \pm 62.5,906 \pm 124 \mathrm{ng} / \mathrm{ml}$ in lean controls and lean TNFR-IgG treated animals and $1250 \pm 125$ and $1092 \pm 127 \mathrm{ng} / \mathrm{ml}$ in obese controls and obese TNFR-IgG treated animals, respectively.

decreased in obese rats $(n=4)$ by $55 \pm 4 \%$ in fat $(P=0.002)$, $68 \pm 6 \%$ in muscle $(P=0.001)$ and $27 \pm 5 \%$ in liver $(P=0.04)$.

Neutralization of TNF- $\alpha$ in obese rats $(n=6)$ increased tyrosine phosphorylation of IRS-1 by $28 \%$ in fat $(P=0.04)$ and $49 \%$ in muscle $(P=0.002)$ compared to obese rats $(n=$

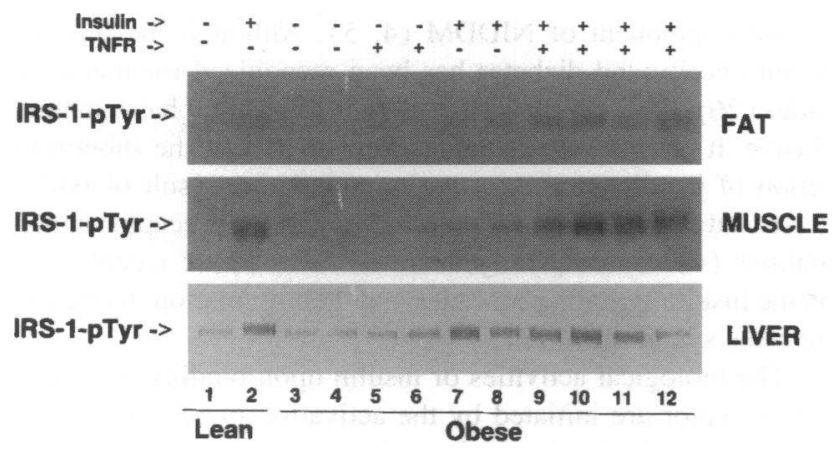

Figure 2. Effects of TNF- $\alpha$ neutralization on insulin-stimulated tyrosine phosphorylation of IRS-1 in tissues from obese ( $\mathrm{fa} / \mathrm{fa}$ ) Zucker rats. The protein extracts were prepared from tissues of lean and obese Zucker rats, before (insulin -) or after (insulin +) intraportal insulin administration. Rats treated with TNFR-IgG to neutralize TNF- $\alpha$ are marked as $\operatorname{TNFR}(+)$ and the controls as $\operatorname{TNFR}(-)$. Lanes $I$ and 2 show the level of insulin-stimulated tyrosine phosphorylation of IRS-1 (IRS-1pTyr) in lean rats. Lanes 3-6 demonstrate IRS-1 phosphorylation at the basal state (before insulin administration ) in both control and TNFRIgG treated obese animals. Lanes 7-12 compare phosphorylation of IRS-1 in control obese (vehicle treated, lanes 7 and 8 ) to TNF-neutralized obese (TNFR treated, lanes 9-12) rats.
4) treated with a vehicle control (Fig. 2). Strikingly, the levels of insulin-stimulated tyrosine phosphorylation of IRS-1 in fat and muscle tissues of TNFR-IgG-treated obese animals were indistinguishable from lean controls. In contrast to muscle and fat tissues, no significant changes were observed in IRS-1 phosphorylation in liver upon TNF neutralization (Fig. 2). These findings are consistent with our previous experiments where we used the same TNF- $\alpha$ neutralization strategy in fa/fa rats to measure effects on insulin-stimulated glucose metabolism. In such experiments TNF- $\alpha$ neutralization caused an increase in insulin-stimulated glucose uptake at peripheral tissues but did not effect the hepatic glucose output (6).

Regulation of protein levels for IR and IRS-1. The results presented above that show an increase in tyrosine phosphorylated IR and IRS-1 after TNF- $\alpha$ neutralization in obese and insulin resistant ( $\mathrm{fa} / \mathrm{fa}$ ) animals could be explained by specific increases in relative phosphorylations of these proteins, or by increased amounts of these proteins, with the same relative phosphate content. To investigate this question, we determined the absolute levels of these proteins. Obese animals exhibited decreases in the quantity of insulin receptors present in all tissues examined. The levels of IR protein in obese fa/fa rats were decreased by $32 \%$ in fat, $41 \%$ in muscle, and $27 \%$ in liver tissues, compared with lean littermates (Fig. 3). When the data on phosphorylation of IR were corrected for changes in the quantity of IR protein, the decreases in fat $(P=0.03)$ and muscle $(P=0.01)$ tissue of obese animals were still significant, being reduced 43.5 and $40.5 \%$, respectively (Fig. 3 ). In contrast, after corrections for IR protein, there was no significant difference in insulin receptor phosphorylation in liver between lean and obese animals (Fig. 3). Importantly, the increases in tyrosine phosphorylations after TNFR treatment occurred in the absence of any significant change in IR protein levels in tissues examined (Fig. 3), demonstrating that TNF- $\alpha$ neutralization specifically increased the ability of insulin to stimulate tyrosine phosphorylation of the IR.

Immunoblots showed no significant changes in IRS-1 protein levels between lean and obese animals in the tissues examined (Fig. 4). The increases in insulin-stimulated tyrosine phosphorylation of IRS-1 in obese animals upon TNF neutralization (Fig. 4) also occurred without any changes in IRS-1 protein levels, in any of the tissues examined. Thus, the neutralization of TNF- $\alpha$ caused increases in the relative tyrosine phosphorylation of IRS-1.

Specificity of the TNFR-IgG effects on insulin-stimulated phosphorylations. It is possible that the neutralization reagent used in this study may increase the tyrosine kinase activity of the IR through an unexpected mechanism that is independent of the obesity-related TNF- $\alpha$ expression. To test the specificity of the effects of TNF- $\alpha$ neutralization observed in the obese animals, we administered equivalent amounts of TNFR-IgG to lean littermates that do not overexpress TNF- $\alpha$ (6). As shown in Fig. 5, TNFR-IgG treatment had no effect on insulin-stimulated tyrosine phosphorylation of IR (Fig. $5 \mathrm{~A}$ ) or IRS-1 (Fig. 5 $B$ ) in lean animals in any of the tissues examined. Similarly, administration of TNFR-IgG had no effect on protein levels of IR and IRS-1 protein in lean animals (see Figs. 3 and 4). In addition, administration of TNFR-IgG alone into the obese animals had no effect on tyrosine phosphorylation of IR or IRS1 in the absence of insulin stimulation. These results strongly suggest that the effects observed in obese animals are due to 


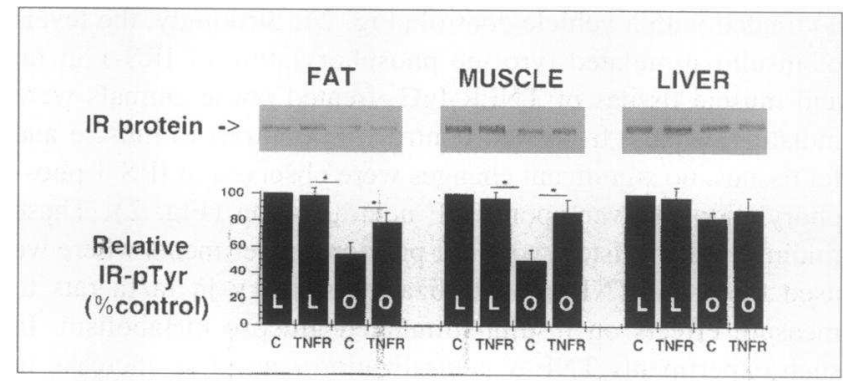

Figure 3. Quantitation of IR protein levels and relative IR phosphorylation in tissues of lean and obese Zucker rats. IR protein was detected by Western blotting and quantitated by digital densitometry, as described in Methods. Representative western blots are shown for each tissue, and the lanes correspond to the bars below. The IR phosphorylation was also quantitated by densitometry and corrected for changes in IR protein quantity. The results are given as mean $\pm \mathrm{SE}$ for each group: lean controls ( $L$ and $C$ ), lean TNF neutralized ( $L$ and TNFR), obese control ( $O$ and $C$ ) and obese TNF neutralized ( $O$ and TNFR) and represented as percent lean controls. The values marked with an asterisk are comparisons that represent statistically significant differences.

specific neutralization of TNF- $\alpha$, which is produced in excess quantities in obese animals.

Effects of TNF- $\alpha$ neutralization on systemic physiology. We have previously shown improvement of insulin sensitivity in $\mathrm{fa} / \mathrm{fa}$ rats upon TNF- $\alpha$ neutralization in a euglycemic clamp protocol (6). Here we investigated the effects of TNF- $\alpha$ neutralization on certain steady-state systemic physiological parameters of animals in the absence of any metabolic manipulation. Plasma glucose, insulin, triglyceride, free fatty acids levels, and body weight values before and after the treatments are summarized in Table I. No significant weight changes were observed in lean and obese rats after vehicle or TNFR-IgG treatments. The small reduction in weight observed in all groups was not statistically significant and probably occurred due to multiple interruptions of feeding for blood collections and intravenous treatments. Plasma glucose levels remained stable in

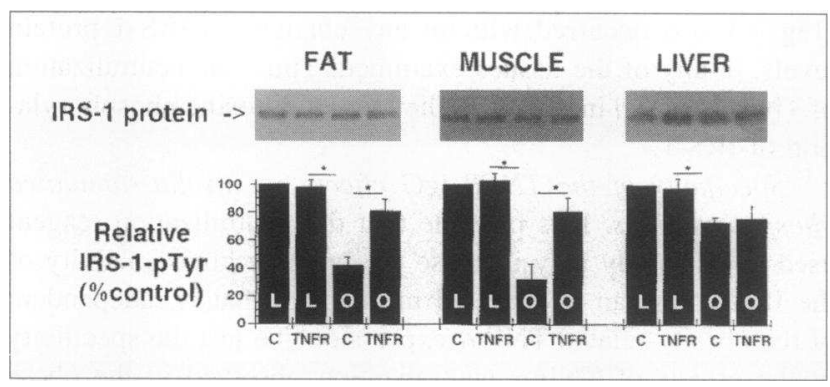

Figure 4. Quantitation of IRS-1 protein levels and relative IRS-1 phosphorylations in tissues from lean and obese Zucker rats. IRS-1 protein was detected by Western blotting and quantitated by digital densitometry, as described in Methods. Representative Western blots are shown for each tissue, and the lanes correspond to the bars below. The IRS-1 phosphorylation was also quantitated by densitometry and no corrections were made since IRS-1 protein levels did not differ between groups. The results are given as mean \pm SE for each group: lean controls ( $L$ and $C$ ), lean TNF neutralized ( $L$ and TNFR), obese control $(O$ and $C$ ) and obese TNF neutralized ( $O$ and TNFR) and represented as percent lean controls. The values marked with an asterisk are comparisons that represent statistically significant differences. lean animals (both control and TNFR-IgG treated). However, obese animals displayed changes in plasma glucose concentrations after the treatments, albeit within normoglycemic boundaries. A $15.8 \%$ increase in plasma glucose was noticed in obese rats that received vehicle treatments (from $173.8 \pm 10.0$ to $201.2 \pm 4.1 \mathrm{mg} / \mathrm{dl}, P=0.04$ ) while a $17.7 \%$ decrease occurred in rats treated with TNFR-IgG (from 193.2 \pm 12.5 to $164.9 \pm 2.6$ $\mathrm{mg} / \mathrm{dl}, P=0.02$ ). At the end of the protocol the plasma glucose levels in obese rats treated with TNFR-IgG were indistinguishable from the lean group $(164.9 \pm 2.6$ and $162.1 \pm 9.6 \mathrm{mg} / \mathrm{dl}$, respectively). However, control obese rats had significantly higher plasma glucose levels compared to lean or TNFR-treated obese animals $(201.2 \pm 4.1,162.1 \pm 9.6$ and $164.9 \pm 2.6 \mathrm{mg} / \mathrm{dl}$, respectively, $P<0.001)$.

Before treatments, plasma insulin levels were significantly higher in obese and insulin-resistant fa/fa rats. The hyperinsulinemia observed in obese animals is believed to be a compensatory mechanism to maintain euglycemia in the presence of insulin resistance. At the end of the protocol, the most dramatic changes were observed in plasma insulin levels where the TNFR-treated obese group showed an $80 \%$ decrease relative to vehicle treatment (from $11.1 \pm 0.55$ to $2.2 \pm 0.45 \mathrm{ng} / \mathrm{ml}$ ) and approached physiologically normal concentrations (Table I). Obese rats also had significant elevations in fasting free fatty acid and triglyceride concentrations in obese rats compared to lean littermates (Table I). No significant changes were observed in triglyceride levels following TNFR-IgG treatments in lean or obese animals. However, a striking decrease was noticed in free fatty acid levels in obese rats following TNF- $\alpha$ neutralization (from $0.521 \pm 0.09$ to $0.213 \pm 0.02 \mathrm{mM}, P<0.001$ ). The small changes seen in other groups were not statistically significant. Since insulin is a powerful antilipolytic agent (4), this reduction in circulating free fatty acid concentrations in TNFRtreated obese rats may be taken as an additional indicator of increased sensitivity to insulin.

\section{Discussion}

Insulin resistance is a ubiquitous correlate of obesity and a central component of NIDDM $(4,5)$. Although the link between obesity and diabetes has been recognized for many decades (26), the molecular basis of this connection has remained elusive. It has been demonstrated, however, that the subnormal action of insulin in obesity is the cumulative result of both a decreased number of insulin receptors and postreceptor abnormalities (4). Consequently, there has been some recent focus on the insulin signaling cascades and their regulation in obesity/ diabetes syndromes (18).

The biological activities of insulin upon binding to its specific receptor are initiated by the activation of the IR tyrosine kinase in the $\beta$ subunit which results in autophosphorylation on multiple tyrosine residues and a subsequent activation in tyrosine kinase activity towards cellular substrates, such as IRS-1 (15-17). The IRS-1 molecule carries multiple phosphorylation sites and has the structural capability of interacting with proteins containing SH2 domains, such as phosphatidylinositol-3-kinase (PI3K; references 17, 18, 27). Current evidence indicates that the tyrosine kinase activity of the insulin receptor is instrumental for insulin action and IRS-1 appears to be a very important molecule in connecting the IR tyrosine kinase with a variety of cellular processes $(18,28,29)$. The possibility that TNF- $\alpha$ might be a key component of insulin resistance via an effect 


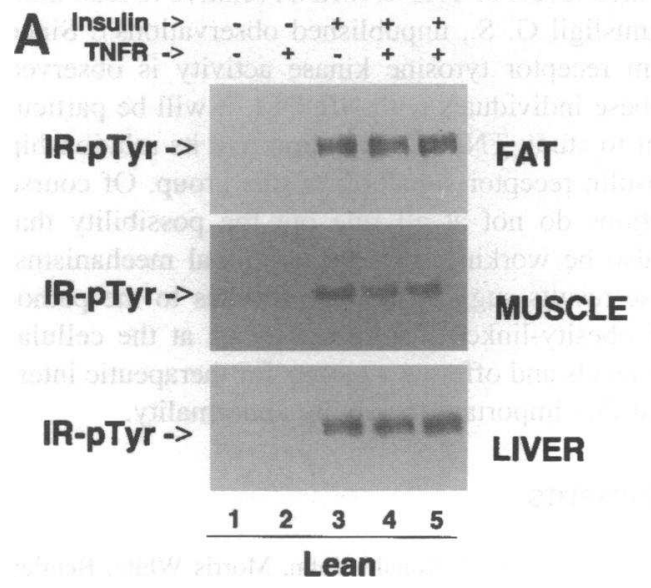

on the IR tyrosine kinase activity is suggested by recent experiments demonstrating such an inhibitory effect in cultured fat and hepatoma cells $(14,19)$. However, the effects of TNF- $\alpha$ on hepatoma cells in culture were somewhat paradoxical since no effect of TNF- $\alpha$ neutralization could be observed in hepatic glucose output in the fa/fa rats (6).

In this paper we have provided clear evidence that TNF- $\alpha$ is playing an inhibitory role on the insulin-stimulated tyrosine phosphorylation cascades in a well-established model of obesity and insulin resistance. Figs. 1 and 2 show that neutralization of TNF- $\alpha$ results in significant increases in insulin-stimulated tyrosine phosphorylations of IR and IRS- 1 in adipose tissue and skeletal muscle indicating that these tissues, critical in glucose homeostasis, are targets for TNF- $\alpha$ action in vivo. These increases occurred without changes in protein levels of IR and IRS-1 (Figs. 3 and 4) in control and TNFR-treated animals (lean or obese). In fat tissue, TNF- $\alpha$ neutralization resulted in a $42 \%$ increase in IR autophosphorylation $(P=0.03)$ and a $28 \%$ increase in IRS-1 phosphorylation $(P=0.04)$, in response
Figure 5. Effects of TNF- $\alpha$ neutralization on insulin-stimulated tyrosine phosphorylation of IR $(A)$ and IRS-1 $(B)$ in fat, muscle and liver tissues from lean Zucker rats. Protein extracts were prepared and analyzed as described in Methods (also see legends for Figs. 1 and 2). IR and IRS-1 tyrosine phosphorylations (IR-pTyr or IRS-1-pTyr) were examined by immunoprecipitations with anti-IR or -IRS-1 antibodies, followed by immunoblotting with MUSCLE anti-phosphotyrosine antibodies. Lanes 1 and 2 demonstrate the basal levels (without insulin stimulation) of IR or IRS-1 phosphorylation in vehicle- and TNFR-treated lean rats. Lanes 3-5 demonstrate insulinstimulated phosphorylations, in vehicle- (lane 3) and TNFR-treated (lanes 4 and 5) lean rats.

Table I. Characteristics of Lean and Obese Zucker Rats Treated with TNFR-IgG

\begin{tabular}{llcccc}
\hline & & Lean Control & Lean TNFR & Obese Control & Obese TNFR \\
\hline & & mean $\pm S E, n=4$ & mean $\pm S E, n=4$ & mean $\pm S E, n=4$ & \\
mean $\pm S E, n=6$ \\
Weight & & & & & \\
Weight & $\mathrm{A}(\mathrm{gram})$ & $203.0 \pm 9.1$ & $272.7 \pm 6.5$ & $437.0 \pm 26.5$ & $410.5 \pm 12.9$ \\
Insulin & $\mathrm{B}(\mathrm{gram})$ & $289.2 \pm 9.4$ & $268.7 \pm 6.3$ & $432.0 \pm 27.1$ & $408.2 \pm 13.7$ \\
Insulin & $\mathrm{A}(\mathrm{ng} / \mathrm{ml})$ & $1.70 \pm 0.33$ & $2.08 \pm 0.51$ & $15.40 \pm 0.56$ & $11.10 \pm 0.55$ \\
Glucose & $\mathrm{B}(\mathrm{ng} / \mathrm{ml})$ & $0.69 \pm 0.04 *$ & $0.62 \pm 0.08^{*}$ & $10.77 \pm 1.50^{*}$ & $2.20 \pm 0.45^{\ddagger}$ \\
Glucose & $\mathrm{A}(\mathrm{mg} / \mathrm{dl})$ & $169.4 \pm 8.1$ & $165.6 \pm 13.0$ & $173.8 \pm 10.0$ & $193.2 \pm 12.5$ \\
Triglcyerides & $\mathrm{B}(\mathrm{mg} / \mathrm{dl})$ & $159.4 \pm 3.1$ & $165.0 \pm 16.2$ & $201.2 \pm 4.1^{*}$ & $164.9 \pm 2.6 *$ \\
Triglycerides & $\mathrm{A}(\mathrm{mg} / \mathrm{dl})$ & $68.97 \pm 7.2$ & $70.11 \pm 2.1$ & $255.8 \pm 39.8$ & $248.8 \pm 48.8$ \\
FFA & $\mathrm{B}(\mathrm{mg} / \mathrm{dl})$ & $74.32 \pm 18.8$ & $74.60 \pm 7.2$ & $225.7 \pm 20.0$ & $237.6 \pm 32.4$ \\
FFA & $\mathrm{A}(\mathrm{mM})$ & $0.133 \pm 0.02$ & $0.157 \pm 0.04$ & $0.460 \pm 0.07$ & $0.521 \pm 0.09$ \\
& $\mathrm{~B}(\mathrm{mM})$ & $0.128 \pm 0.03$ & $0.139 \pm 0.04$ & $0.396 \pm 0.06$ & $0.213 \pm 0.02^{\ddagger}$
\end{tabular}

${ }^{*} P$ value $<0.05$ (two tailed student $t$ test). $\quad{ }^{\ddagger} P$ value $<0.005$ (two tailed student $t$ test). $A$, before TNFR- or vehicle treatments. $B$, after TNFR- or vehicle treatments. 
in obesity and are believed to contribute to systemic insulin resistance (4). It is clear from data presented here that free fatty acid levels in obese animals are modulated by TNF- $\alpha$, presumably via control of insulin sensitivity of the adipose mass (see below). Along the same lines, there could be other molecules that are regulated in fat by TNF- $\alpha$ through autocrine mechanisms and then affect insulin sensitivity of muscle via paracrine or endocrine pathways. The precise mode of inhibition of the IR tyrosine kinase activity in muscle by TNF- $\alpha$ in vivo will require further investigation.

In contrast to our observations in fat and muscle, no significant changes in insulin signaling were observed in liver upon TNF- $\alpha$ neutralization. It is worth noting, however, that the differences in IR signaling between the lean and obese animals were marginal in liver tissue even before the TNF neutralization. Previous experiments using the identical neutralization reagent and regimen, have also failed to demonstrate an effect of TNF$\alpha$ neutralization on hepatic glucose output in fa/fa rats, despite a significant increase occurred in insulin-stimulated glucose disposal (6). This lack of effectiveness on liver may be due to different mechanisms involved in hepatic insulin resistance which can not be overcome by TNF- $\alpha$ neutralization alone. Alternatively, the neutralization reagent and/or method may not have been optimal to achieve complete inactivation of TNF- $\alpha$ in vivo, thus sparing some residual TNF activity which affects liver. The observation that TNF- $\alpha$ blocks insulin signaling in hepatoma cells (19) suggests that liver may be a potential target TNF- $\alpha$. Therefore, the lack of in vivo action on liver may be indicative of absence of TNF- $\alpha$ in the circulation (so that liver is not exposed to this cytokine) and is consistent with the potential autocrine/paracrine mode of action of adipose-born TNF- $\alpha$. Nevertheless, the role of TNF- $\alpha$ in interfering with insulin action in the liver will require more study, including the complete inactivation of TNF- $\alpha$ or its receptors using genetic ablation approaches.

If the normalization in insulin-stimulated tyrosine phosphorylations upon TNF- $\alpha$ neutralization has physiological significance, it might be expected that some hallmarks of abnormal metabolism resulting from insulin resistance might be improved in the fa/fa rats. This was indeed the case for several important metabolic parameters. First, and most strikingly, the compensatory hyperinsulinemia of these obese animals was dramatically reduced to near lean levels after TNF-neutralization (Table I). Second, TNFR-IgG treated animals had lower plasma glucose concentrations at the end of the protocol compared with obese rats treated with vehicle $(P<0.05)$. Although none of the obese animals were significantly hyperglycemic during the experimental period, maintaining euglycemia without hyperinsulinemia is a strong indicator of increased insulin sensitivity in animals that received TNFR-IgG (4). Finally, TNF- $\alpha$ neutralization also resulted in a significant decrease in circulating free fatty acid concentrations in obese animals. This effect presumably reflects an improvement in insulin-mediated suppression of lipolysis in adipose tissue. In contrast, no significant changes were observed in triglyceride levels in any of the animals. Although these findings may be explained on the basis of differential roles of liver and adipose tissue (which are differentially affected by TNF- $\alpha$ ) in the regulation of lipid metabolism through lipogenesis and lipolysis, understanding the full impact of TNF- $\alpha$ neutralization on lipid metabolism will require further investigation.

In summary, the data presented here establishes a mecha- nism whereby TNF- $\alpha$ is involved in obesity-linked insulin resistance through its ability to interfere with insulin-stimulated tyrosine phosphorylation cascades. Preliminary data suggests that the adipose tissue of obese humans with insulin resistance also expresses elevated levels of TNF- $\alpha$ mRNA relative to lean individuals (Hotamisligil G. S., unpublished observations). Since reduced insulin receptor tyrosine kinase activity is observed primarily in obese individuals with NIDDM, it will be particularly important to study TNF- $\alpha$ expression and its relationship to deficient insulin receptor signaling in this group. Of course these observations do not at all rule out the possibility that TNF- $\alpha$ may also be working through additional mechanisms. However, these results suggest new approaches to the pathophysiology of obesity-linked insulin resistance at the cellular and molecular levels and offer new targets for therapeutic intervention to treat this important metabolic abnormality.

\section{Acknowledgments}

We would like to thank Drs. C. Ronald Kahn, Morris White, Bentley Cheatham, and Martin Myers (Joslin Diabetes Center) for generously providing various antibodies and helpful advice, Dr. David Goeddel (Genentech, Inc.) for TNFR-IgG, and Dr. Thomas Roberts for antiphosphotyrosine antibodies.

This work was supported by National Institutes of Health grant from DK-42539.

\section{References}

1. Grunfeld, C., and K. R. Feingold. 1992. Metabolic disturbances and wasting in the acquired immunodeficiency syndrome. N. Engl. J. Med. 327:329-337.

2. Copeland, G. P., S. J. Leinster, J. C. Davis, and L. J. Hipkin. 1987. Insulin resistance in patients with colorectal cancer. Br. J. Surg. 74:1031-1035.

3. Tayek, J. A. 1992. A review of cancer cachexia and abnormal glucose metabolism in humans with cancer. J. Am. Col. Nutr. 11:445-456.

4. Moller, D. E. 1993. Insulin Resistance. John Wiley and Sons Ltd., UK

5. Moller, D. E., and J. S. Flier. 1992. Insulin resistance: mechanisms, syndromes, and implications. N. Engl. J. Med. 325:938-948.

6. Hotamisligil, G. S., N. S. Shargill, and B. M. Spiegelman. 1993. Adipose expression of tumor necrosis factor-alpha: direct role in obesity-linked insulin resistance. Science (Wash. DC). 259:87-91.

7. Hotamisligil, G. S., and B. M. Spiegelman. 1993. Through thick and thin: wasting, obesity, and TNF alpha. Cell. 73:625-627.

8. Hofmann, C., K. Lorenz, S. S. Braithwaite, J. R. Colca, B. J. Palazuk, G. S. Hotamisligil, and B. M. Spiegelman. 1994. Altered gene expression for tumor necrosis factor- $\alpha$ and its receptors during drug and dietary modulation of insulin resistance. Endocrinology. 134:264-270.

9. Lang, C. H., C. Dobrescu, and G. J. Bagby. 1992. Tumor necrosis factor impairs insulin action on peripheral glucose disposal and hepatic glucose output. Endocrinology. 130:43-52.

10. Cornelius, P., M. D. Lee, M. Marlowe, and P. H. Pekala. 1989. Monokine regulation of glucose transporter mRNA in L6 myotubes. Biochem. Biophys. Res. Commun. 165:429-436.

11. Stephens, J. M., and P. H. Pekala. 1991. Transcriptional repression of the GLUT4 and C/EBP genes in 3T3-L1 adipocytes by tumor necrosis factor-alpha. J. Biol. Chem. 266:21839-21845.

12. Pederson, O., C. R. Kahn, and B. B. Kahn. 1992. Divergent regulation of the Glut1 and Glut4 glucose transporters in isolated adipocytes from Zucker rats. J. Clin. Invest. 89:1964-1973.

13. Garvey, W. T., L. Maianu, T. P. Huecksteadt, M. J. Birnbaum, J. M Molina, and T. P. Ciaraldi. 1991. Pretranslational suppression of a glucose transporter protein causes insulin resistance in adipocytes from patients with noninsulin dependent diabetes mellitus and obesity. J. Clin. Invest. 87:1072-1081.

14. Hotamisligil, G. S., D. L. Murray, L. N. Choy, and B. M. Spiegelman 1994. TNF- $\alpha$ inhibits signaling from insulin receptor. Proc. Natl. Acad. Sci. USA. 91:4854-4858.

15. Kasuga, M., F. A. Karlsson, and C. R. Kahn. 1982. Insulin stimulates the phosphorylation of the 95:000-dalton subunit of its own receptor. Science (Wash. DC). 215:185-187.

16. White, M. F., R. Maron, and C. R. Kahn. 1985. Insulin rapidly stimulates tyrosine phosphorylation of a Mr-185:000 protein in intact cells. Nature (Lond.). 318:183-186. 
17. Sun, X. J., P. Rothenberg, C. R. Kahn, J. M. Backer, E. Araki, P. A. Wilden, D. A. Cahill, B. J. Goldstein, and M. F. White. 1991. Structure of the insulin receptor substrate IRS-1 defines a unique signal transduction protein. Nature (Lond.). 352:73-77.

18. White, M. F., and C. R. Kahn. 1994. The insulin signaling system. J. Biol. Chem. 269:1-4.

19. Feinstein, R., H. Kanety, M. Z. Papa, B. Lunenfeld, and A. Karasik. 1993. Tumor necrosis factor- $\alpha$ suppresses insulin-induced tyrosine phosphorylation of insulin receptor and its substrates. J. Biol. Chem. 268:26055-26058.

20. Thies, R. S., J. M. Molina, T. P. Ciaraldi, G. R. Freidenberg, and J. M. Olefsky. 1990. Insulin-receptor autophosphorylation and endogenous substrate phosphorylation in human adipocytes from control, obese, and NIDDM subjects. Diabetes. 39:250-259.

21. Saad, M. J. A., E. Araki, M. Miralpeix, P. L. Rothenberg, M. F. White, and C. R. Kahn. 1992. Regulation of insulin receptor substrate-1 in liver and muscle of animal models of insulin resistance. J. Clin. Invest. 90:1839-1849.

22. Folli, F., M. J. Saad, J. M. Backer, and C. R. Kahn. 1992. Insulin stimulation of phosphatidylinositol 3-kinase activity and association with insulin receptor substrate 1 in liver and muscle of the intact rat. J. Biol. Chem. 267:22171-22177.

23. Heydrick, S. J., D. Jullien, N. Gautier, J.-F. Tanti, S. Giorgetti, E. V. Obberghen, and Y. Le Marchand-Brustel. 1993. Defect in skeletal muscle phos-
phatidylinositol-3-Kinase in obese insulin-resistant mice. J. Clin. Invest. 91:13581366.

24. Laemmli, U. K. 1970. Cleavage of structural proteins during the assembly of the head of bacteriophage T4. Nature (Lond.). 227:680-685.

25. White, M. F. 1990. In Peptide Hormone Action: A Practical Approach, K. Siddle, and J. C. Hutton, editors.. IRL Press, Oxford, U.K. 223-250.

26. Himmsworth, H. P. 1939. The mechanisms of diabetes mellitus. IV. Human diabetes mellitus. Lancet. 2:171-176.

27. Myers, M. G. Jr., J. M. Backer, X. J. Sun, S. Shoelson, P. Hu, J. Schlessinger, M. Yoakim, B. Schaf fhausen, and M. F. White. 1992. IRS-1 activates phosphatidylinositol $3^{\prime}$-kinase by associating with src homology 2 domains of p85. Proc. Natl. Acad. Sci. USA 89:10350-10354.

28. Wilden, P. A., K. Siddle, E. Haring, J. M. Backer, M. F. White, and C. R. Kahn. 1992. The role of insulin receptor kinase domain autophosphorylation in receptor-mediated activities. Analysis with insulin and anti-receptor antibodies. J. Biol. Chem. 267:13719-13727.

29. Wang, L.-M., M. G. Myers, Jr., X.-J. Sun, S. A. Aaronson, M. White and J. H. Pierce. 1993. IRS-1 is essential for insulin- and IL-4-stimulated mitogenesis in hematopoietic cells. Science (Wash. DC). 261:1591-1594.

30. Cotran, R. S., V. Kumar, and S. L. Robbins, editors. 1989. Pathological Basis of Disease. 4th edition. W.B. Saunders Company, Philadelphia, PA. 2223. 